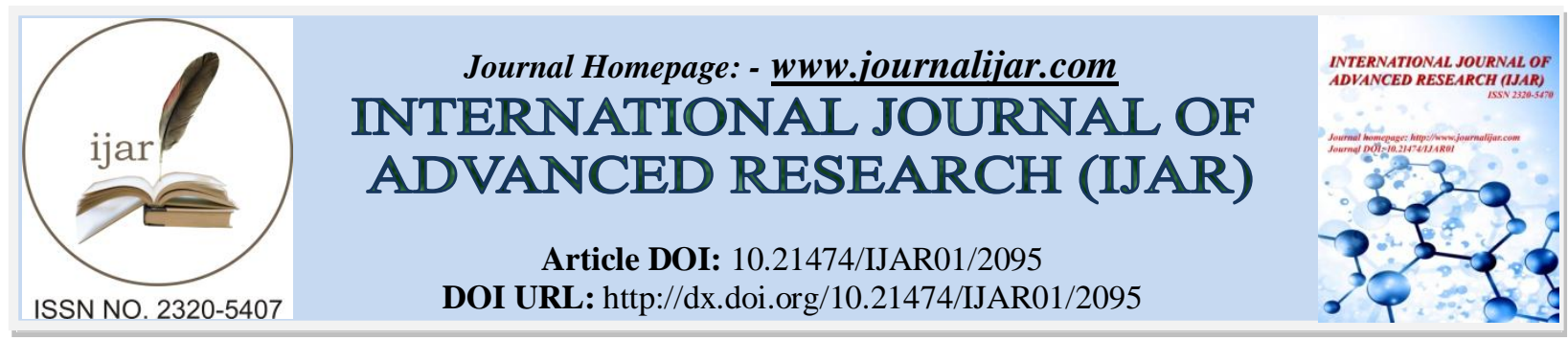

RESEARCH ARTICLE

\title{
EXPERIMENTAL INVESTIGATION ON STRENGTH PROPERTIES OF CONCRETE WITH BAGASSE ASH AND QUARRY DUST.
}

\section{S. Azhagarsamy and K. Jaiganesan.}

Assistant Professor, Department of Civil Engineering, Mailam Engineering College, Mailam, Villupuram District, Tamil Nadu 604304.

\section{Manuscript Info}

Manuscript History

Received: 24 September 2016

Final Accepted: 26 October 2016

Published: November 2016

Key words:-

Compressive Strength, Sugarcane

Bagasse Ash, Silica Fume and quarry

dust.

\section{Abstract}

This experimental study investigates the compressive and split tensile strength of concrete using Portland pozzolana Cement and Sugarcane Bagasse Ash, silica fume, Quarry Dust and hence improving the strength of concrete. This work evaluates the performance of Sugarcane Bagasse Ash (BA) as a mineral admixture in concrete having the w/c ratio of 0.40 . Concrete was replaced with BA $10 \%, 20 \%$ and $30 \%$ and silica fume $10 \%$ in common and also replaced with quarry dust for fine aggregate with $20 \%$ and $30 \%$ for M45 mix. The strength properties are compared with the above varying percentage and found that the mix of $10 \% \mathrm{BA}$ and $30 \%$ M-Sand was comparably shown a better performance than the conventional concrete.

Copy Right, IJAR, 2016,. All rights reserved.

\section{Introduction:-}

Concrete is a mixture of cement, sand, coarse aggregate and water. Ordinary Portland cement is recognized as the major construction material throughout the world. Industrial wastes, such as blast furnace slag, fly ash and silica fume are being used as supplementary cement replacement materials. In addition to these, agricultural wastes such as rice husk ash, wheat straw ash, and sugarcane bagasse ash are also being used as pozzolanic materials and hazel nutshell used as cement replacement material [1]. India being one of the largest producers of sugarcane in the world produces 300 million tons per year [2] and large quantity of sugarcane bagasse is available from sugar mills. Sugarcane bagasse is partly used as fuel at the sugar mill. Only a few studies have been reported on the use of bagasse ash (BA) as pozzolanic material in respect of cement paste [5]. Bagasse is a by-product from the sugar industry and it is usually burnt at the mill to provide process power or steam. The resultant ash is a pozzolanic material that would otherwise require disposal $[4,5,7]$. The sugarcane bagasse consists of approximately $50 \%$ of cellulose, $25 \%$ of hemicelluloses and $25 \%$ of lignin. Each ton of sugarcane generates approximately $26 \%$ of bagasse (at a moisture content of 50\%) and $0.62 \%$ of residual ash. The residue after combustion presents a chemical composition dominates by silicon dioxide ( $\mathrm{SiO} 2)$. In spite of being a material of hard degradation and that presents few nutrients, the ash is used on the farms as a fertilizer in the sugarcane harvests. Report shown that the strength of concrete is reduced when the percentage of $\mathrm{BA}$ is increased beyond $10 \%[1,5]$.Researches has also been carried out for different percentage of BA as replacement of OPC. Further replacement of cement by bagasse ash results in better or similar concrete properties and further environmental and economical advantages can also be exploited by using bagasse ash as a partial cement replacement material [3]. The present study involves the combination of BA and M-Sand which gives a better perspective on the strength behavior of concrete.

Corresponding Author:- S. Azhagarsamy.

Address:- Assistant Professor, Department of Civil Engineering, Mailam Engineering College, Mailam, Villupuram District, Tamil Nadu 604304. 


\section{Materials:-}

The Ordinary Portland cement of 53-grade was used in this study conforming to IS: 12269-1987 [9]. The river sand is used as fine aggregate conforming to the requirements of IS: 383-1970 [10]. Coarse aggregate obtained from local quarry units has been used for this study, conforming to IS: 383-1970 [10]. The water used for experiments was potable water conforming as per IS: 456-2000 [11]. The Quarry Dust is used as fine aggregate in accordance with BIS 2386-1963. Sugarcane bagasse ash was collected from the Ponni Sugars Limited, Erode. Bagasse ash used in this study was obtained by burning BA at $600^{\circ} \mathrm{C}$ for 5 hours under controlled conditions. The specific gravity of silica fume is 2.2. It consists of 0.1 to 1 micron sized fine, smooth spherical glassy particles with fineness of $20 \mathrm{~m}^{2} / \mathrm{gm}$ conforming to ASTM C1240-1999 standards.

\section{Experimental Procedure:-}

Concrete was produced with $10 \%, 20 \%$ and $30 \%$ of the BA as cement replacement (by weight), $10 \%$ of silica fume in common and sand is replaced by M-Sand with $20 \%$ and 30\% (by weight) with w/c ratio of 0.40 . Ratio for M45 Grade as per IS 10262:2009 (1:1.48:1.90) the mixes were designated in accordance with IS: 10262-2009 [10]. The compressive and split tensile strength of the same was observed for 3, 7 and 28 days. A total of 63 cubes and 63 cylinders were casted during the experimental program. Ordinary water curing was done through the experimental study.

Table 1. Comparison of Compressive Strength of Cubes with Bagasse ash and M-Sand

\begin{tabular}{|l|l|l|l|}
\hline$\%$ Replacement of (BA and MS) & 3 Days & 7 Days & 28 Days \\
\hline CC & 22.5 & 35.3 & 47.3 \\
\hline BA 10\%+ QD 20\% & 24.5 & 38.5 & 53.8 \\
\hline BA 20\%+ QD 20\% & 22.9 & 34.3 & 49.3 \\
\hline BA 30\%+ QD 20\% & 21.3 & 33.02 & 48.6 \\
\hline BA 10\%+ QD 30\% & 25.7 & 39.8 & 54.2 \\
\hline BA 20\%+ QD 30\% & 23.1 & 37.6 & 51.7 \\
\hline BA 30\%+ QD 30\% & 22.7 & 34.58 & 49.4 \\
\hline
\end{tabular}

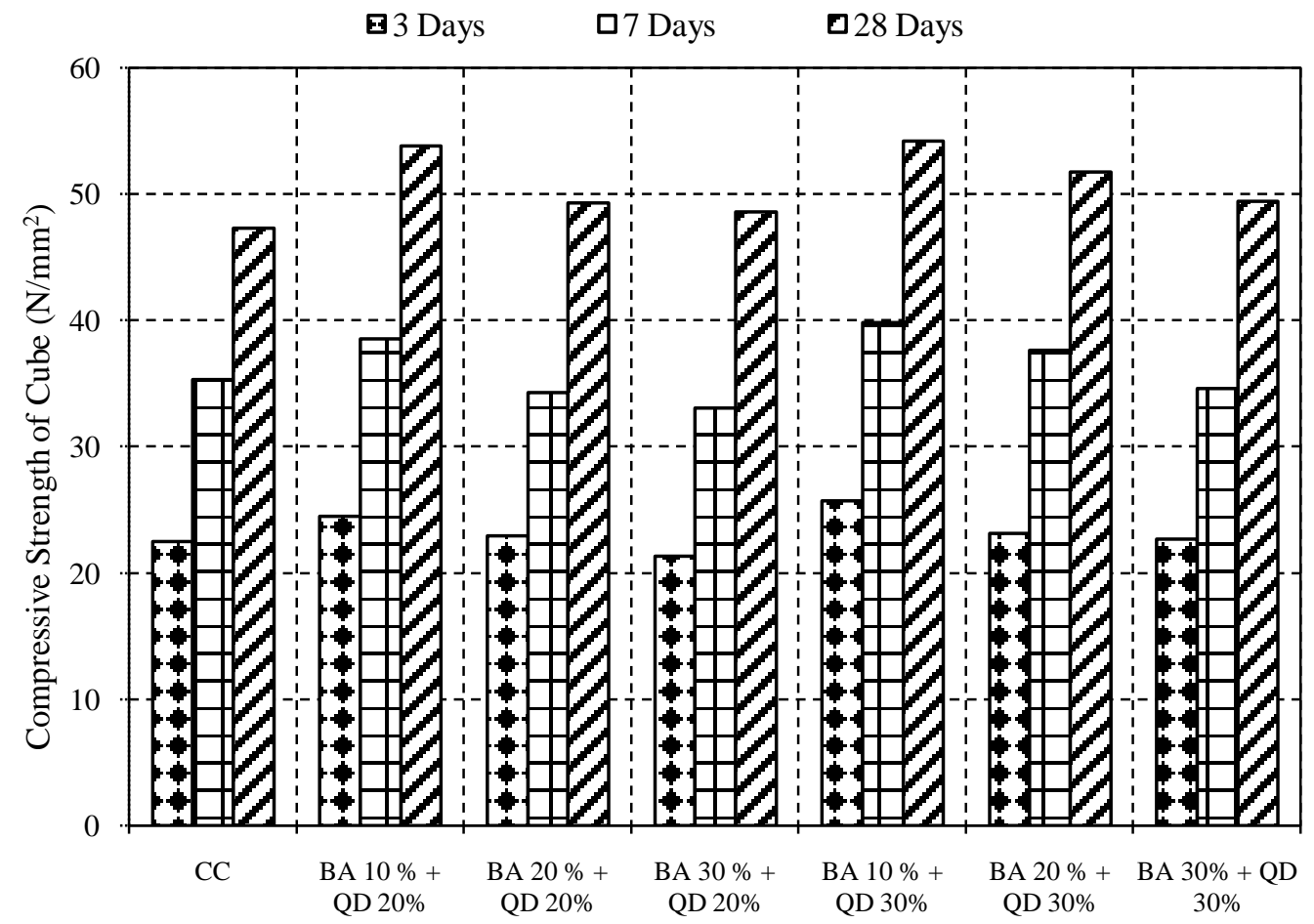

Fig 1:- Comparison of Compressive Strength of Cubes on 3, 7 and 28 Days 
Table 2:- Comparison of Split tensile Strength of Cylinder with Bagasse ash and M-Sand

\begin{tabular}{|l|l|l|l|}
\hline$\%$ Replacement of (BA and MS) & 3 Days & 7 Days & 28 Days \\
\hline CC & 1.69 & 3.26 & 5.16 \\
\hline BA 10\%+ QD 20\% & 3.78 & 5.67 & 8.697 \\
\hline BA 20\%+ QD 20\% & 2.44 & 4.78 & 6.786 \\
\hline BA 30 + QD 20\% & 1.24 & 3.88 & 5.544 \\
\hline BA 10\%+ QD 30\% & 4.66 & 6.53 & 9.322 \\
\hline BA 20\%+ QD 30\% & 3.66 & 5.37 & 7.677 \\
\hline BA 30\%+ QD 30\% & 2.84 & 3.98 & 5.698 \\
\hline
\end{tabular}

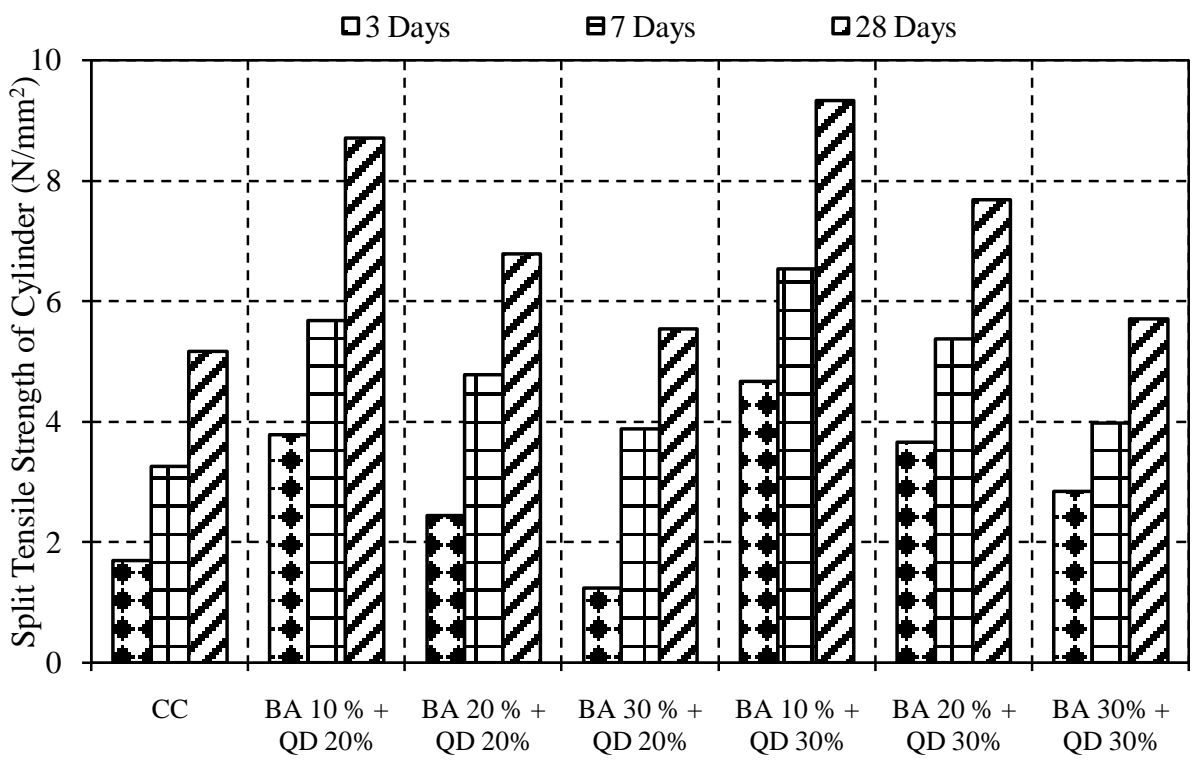

Fig 2:- Comparison of Split Tensile Strength of Cylinders on 3, 7 and 28 Days

\section{Results and Discussion:-}

The compressive and split tensile strength of M45 grade concrete mix the following result are observed.

1. For M45 grade concrete the compressive strength at the end of 3, 7 and 28 days for BA $10 \%$ and QD $20 \%$ the compressive strength showed an increasing value of $24.5,38.5$ and $53.8 \mathrm{~N} / \mathrm{mm}^{2}$ as shown in Fig 1 .

2. A similar trend of decreasing value was observed when the BA increased to $20 \%, 30 \%$ and QD $20 \%$ the value obtained at the end of 28days for 49.3 and $48.6 \mathrm{~N} / \mathrm{mm}^{2}$ at the end of 28days as shown in Table 1.

3. A gradually increase of QD $20 \%$ to $30 \%$ and BA $10 \%$ showed an increasing trend in the compressive strength at the end of 3, 7 and 28days for $25.7,39.8$ and $54.3 \mathrm{~N} / \mathrm{mm}^{2}$.

4. A similar trend of decreasing value was observed when the BA increased to $20 \%, 30 \%$ and QD $30 \%$ the value obtained at the end of 28days for 51.7 and $49.4 \mathrm{~N} / \mathrm{mm}^{2}$ at the end of 28days as shown in Table 1 .

5. The split tensile strength at the end of 3, 7 and 28 days for BA $10 \%$ and QD $20 \%$ the split tensile strength showed an increasing value of 3.78, 5.67 and $8.697 \mathrm{~N} / \mathrm{mm}^{2}$ as shown in Fig 2.

6. A similar trend of decreasing value was observed when the BA increased to $20 \%, 30 \%$ and QD $20 \%$ the value obtained at the end of 28days for 6.786 and $5.544 \mathrm{~N} / \mathrm{mm}^{2}$ at the end of 28days as shown in Table 2.

7. A gradually increase of QD $20 \%$ to $30 \%$ and BA $10 \%$ showed an increasing trend in the split tensile strength at the end of 3, 7 and 28days for $4.66,6.53$ and $9.322 \mathrm{~N} / \mathrm{mm}^{2}$.

8. A similar trend of decreasing value was observed when the BA increased to $20 \%, 30 \%$ and QD $30 \%$ the value obtained at the end of 28 days for 7.677 and $5.698 \mathrm{~N} / \mathrm{mm}^{2}$ at the end of 28days as shown in Table 2.

\section{Conclusions:-}

A maximum Compressive strength was found for 10\% BA and 30\% QD in M45 grade of concrete. Hence the concrete showed a better performance with respect to its compressive and split tensile properties. Since bagasse ash 
is a by-product material used as a cement replacing material reduces the levels of $\mathrm{CO} 2$ emission by the cement industry and also economical in nature. The compressive strength of concrete decreases with increase in percentage of BA.

\section{References:-}

1. Amrita Kumari, Sheo Kumar, "Experimental Study on Partial Replacement of Cement by Sugarcane Bagasse Ash" International Journal of Innovative Research in Science, Engineering and Technology, Vol. 4, Issue 7, July 2015.

2. Balasubramanian SV, Ratnavelu KN. Budget performance of sugar industry: 2000-2001. In: Proceeding of South India sugar mills association 2001, India.

3. BirukHailu and AbebeDinku, Application of Sugarcane Bagasse Ash as a partial cement replacement material, $1-21$.

4. Ganesan, K., Rajagopal, K., \& Thangavel, K. 2007. Evaluation of bagasse ash as supplementary cementitious material. Cement and Concrete Composites, 29, 515-524.

5. Hernandez JM, Middendorf B, Gehrke M, Budelmann H. Use of wastes of the sugar Industry as pozzolana in lime-pozzolana binders: study of the reaction. Cem Concr Res 1998; 28(11): 1525-36.

6. Martirena JF, Middendorf B, Gehrke M, Budelmann H, (1998) Use of wastes of sugar industry as pozzolana in lime-pozzolana binders: study of the reaction, Cement and Concrete Research, 28, pp. 1525-1536.

7. Nuntachai Chusilp1, Napongsatorn Likhitsripaiboon and Chai Jaturapitakkul, "Development of bagasse ash as a pozzolanic material in concrete" Asian Journal on Energy and Environment, 2009, 149-159.

8. Singh NB, Singh VD, Rai S, (2000) Hydration of bagasse ash-blended Portland cement, Cement and Concrete Research, 30, pp. 1485-1488.

9. Is: 12269-1987, Specification for53 grade ordinary Portland cement, B.I.S., New Delhi.

10. I.S.: 383 - 1970, Indian standard specification for coarse \& fine aggregates from natural sources for concrete, B.I.S., New Delhi.

11. I.S.: 456 - 2000, Indian standard Specification for plain and reinforced concrete - code of practice. (Fourth revision), B.I.S., New Delhi.

12. IS 10262 -2009 "IS Method of Mix Design", Bureau of Indian Standards, New Delhi.

13. IS 516-1959 "Methods of Tests for strength of concrete", Bureau of Indian Standards, New Delhi. 